\title{
Egipto en Tenerife. Los rostros del intercambio
}

\author{
Eduardo ALMENARA ROSALES \\ Candelaria MARTÍN DEL RÍO ÁLVAREZ
}

El trabajo presentado a este Congreso en forma de póster pretende ser un anexo al libro Colección de vasos egipcios del Museo Municipal de Bellas Artes de Santa Cruz de Tenerife, editado en 2000. Esta obra recoge tanto la historia del intercambio como la catalogación y contexto histórico de las piezas que llegaron a la isla, como resultado del trato realizado en 1908 entre la institución que las custodia ahora y el Museo de Liverpool. Desde entonces, el descubrimiento de nueva información cubre algunas de las lagunas que se dejaron entonces de este singular evento.

\section{Egipto en Tenerife. The human face of the exchange}

The work presented to this Congress as a poster, means to be an appendix to the book Colección de vasos egipcios del Museo Municipal de Bellas Artes de Santa Cruz de Tenerife, edited in 2000. It reflects both the exchange and cataloguing as well as the historical context of the pieces that arrived to the island as the consequence of a deal that took place in 1908 with the Liverpool Museum. Since that moment, the discovery of new information covers some doubts of this singular event.

KeY wORDs: Naqada II, Dynasty 0, Middle Kingdom, W.M.F. Petrie, J. Garstang, Egypt Exploration Fund

$\mathrm{E}_{\mathrm{g}}^{\mathrm{n}}$ n el momento de la publicación del catálogo que acompañaba la exposición Egipto en Tenerife. Historia de un intercambio (Almenara Rosales y Martín del Río Álvarez, 2000a), se había obtenido una información sobre las biografías de los protagonistas y otros datos históricos que resultaba incompleta en algunos aspectos. El problema radicaba en que los indicios de búsqueda eran escasos y los archivos del Museo de Liverpool estaban aún siendo recuperados y reorganizados. Posteriormente, hemos continuado indagando datos indirectos y directos, lo que nos ha llevado a contactar con diferentes personas y entidades. El actual conservador de la sección egipcia del Museo de Liverpool, Ashley Cooke, y la investigadora de la familia Entwistle, Barbara Nightingale, nos cedieron valiosa información biográfica y fotos de gran interés que sirvieron para reconocer y

Fecha de recepción: 2 de abril de 2008 dar imagen a algunos de los protagonistas olvidados de esta historia. Las consultas online del Registro Civil británico y de diversos sitios web relacionados con los barcos y la Primera Guerra Mundial, fueron decisivas para terminar de cumplimentar la mayor parte del rompecabezas de este intercambio.

Con el propósito de hacer más comprensible este trabajo, proponemos una breve referencia retrospectiva sobre el hecho histórico que lo generó. A comienzos de 1908, Peter Entwistle, por ese tiempo conservador del Museo de Liverpool, estuvo de vacaciones en Tenerife. La estancia en la isla lo llevó a visitar el Museo Municipal de Bellas Artes de Santa Cruz de Tenerife, cuya sede provisional se encontraba en obras. El recinto había sido un convento franciscano antes de las desamortizaciones.

Fecha de admisión: 10 de mayo de 2008 


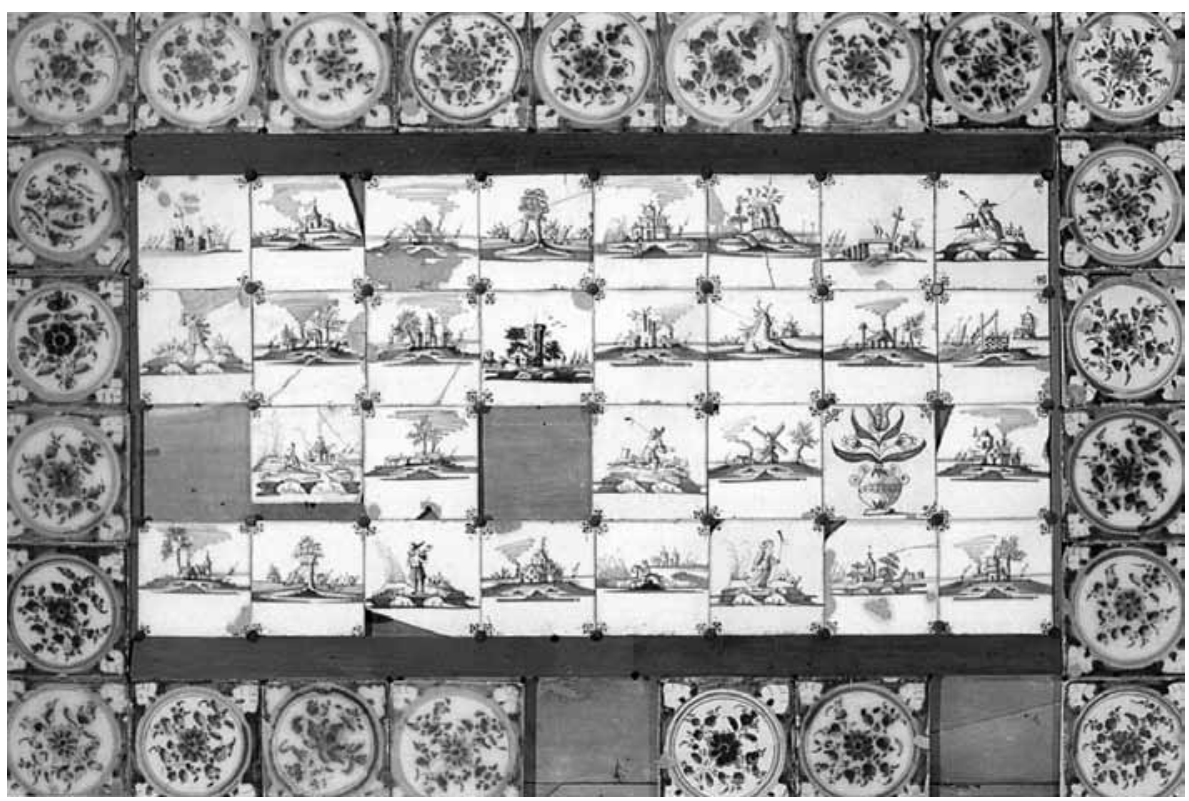

Figura 1. Panel de azulejos holandeses

En él destacaba una torre de cuya cúpula se estaba desmontando en esos días la cobertura de azulejos holandeses y de Talavera del siglo XVII. Éstos atrajeron la atención del visitante británico quien solicitó una entrevista con Teodomiro Robayna, director de la institución. En ella se planteó un principio de acuerdo para intercambiar recipientes del Egipto antiguo por un grupo de azulejos. De estos últimos, aún se conservan diversos paneles con ejemplares similares en los fondos del Museo tinerfeño (fig. 1) (Almenara Rosales y Martín del Río Álvarez, 2000b).

[42 ]

A los pocos días de su llegada a Liverpool, gestionó el permiso para la realización de lo acordado y seleccionó el grupo de objetos egipcios que enviaría: once recipientes cerámicos y un soporte, además de un vaso de piedra (fig. 2). Estas piezas procedían de las excavaciones de William M. Flinders Petrie ${ }^{1}$ y de John Garstang ${ }^{2}$. Intentó que la selección cubriera un amplio espacio temporal y así, incluyó ejemplares predinásticos y dinásticos, pudiendo destacar entre ellos un vaso de Borde negro (B18k) de Naqada I (Diospolis Parva) y un modelo de piedra hallado en la tumba B7 del monarca Horus Ka (Umm el-Qaab). Estos objetos estuvieron expuestos en el Museo de Bellas Artes hasta 1959, cuando fueron retirados a sus almacenes, lugar donde se encuentran, de manera incomprensible, todavía hoy. Sólo han visto la luz temporalmente, para ser los protagonistas de una exposición sobre su origen y periplo, en el año 2000, dentro de las actividades conmemorativas del centenario de la fundación de la institución.

1. Procedentes de las campañas de Petrie en Dióspolis Parva en 1898-99; y de Ábidos, en 1909 (Umm el-Qab, tumba B7). Almenara Rosales y Martín del Río Álvarez, 2000a: 58-60, 103-104, 108-109, 132-133.

2. Procedentes de las campañas de Garstang de 1906-1907 en el Cementerio HK27 de Hieracómpolis (enterramientos 142 y 156) y de Hagar Esna (tumbas 77, 139, 183, 264, 336, 346). Almenara Rosales y Martín del Río Álvarez, 2000a: 61-96, 110-131. 
Esta pequeña colección presenta un indudable interés más allá del entorno cultural de las Islas Canarias y de la Egiptología española, no sólo por sus propias características y cronología, sino también porque su identificación y posterior análisis han permitido rehabilitarlas en la realidad museística. Debemos tener en cuenta que estas piezas habían sido declaradas por el Museo de Liverpool como desaparecidas durante los ataques alemanes a la ciudad en 1941, momento en que perdieron gran parte de su colección egipcia y sus archivos.

Centrándonos en los personajes de esta historia, comenzaremos el recorrido por las personas que ejercían la dirección de los museos en el momento del intercambio. En el tinerfeño se encontraba Teodomiro Robayna, un eminente artista de la isla, profesor de la Escuela de Bellas Artes de la capital y cofundador del Museo (fig. 3). Sin duda, la oferta del canje fue un golpe de suerte, ya que la nueva sede abría sus puertas unos meses después y las piezas serían un aliciente más de sus salas. Esto queda ratificado por los artículos de la prensa local que cubrió la inauguración, pues subrayaron la presencia de la colección egipcia y la de los azulejos entre los objetos expuestos (Almenara Rosales y Martín del Río Álvarez, 2000a: 4). La institución inglesa estaba a cargo de Henry Ogg Forbes, un eminente explorador, ornitólogo y botánico escocés, al que se debe la catalogación de diversos especímenes del área de Nueva Guinea (fig. 4). Inició su carrera museística en Nueva Zelanda y la finalizó en Liverpool. Su interés profesional generó otra circunstancia anecdótica, pues según

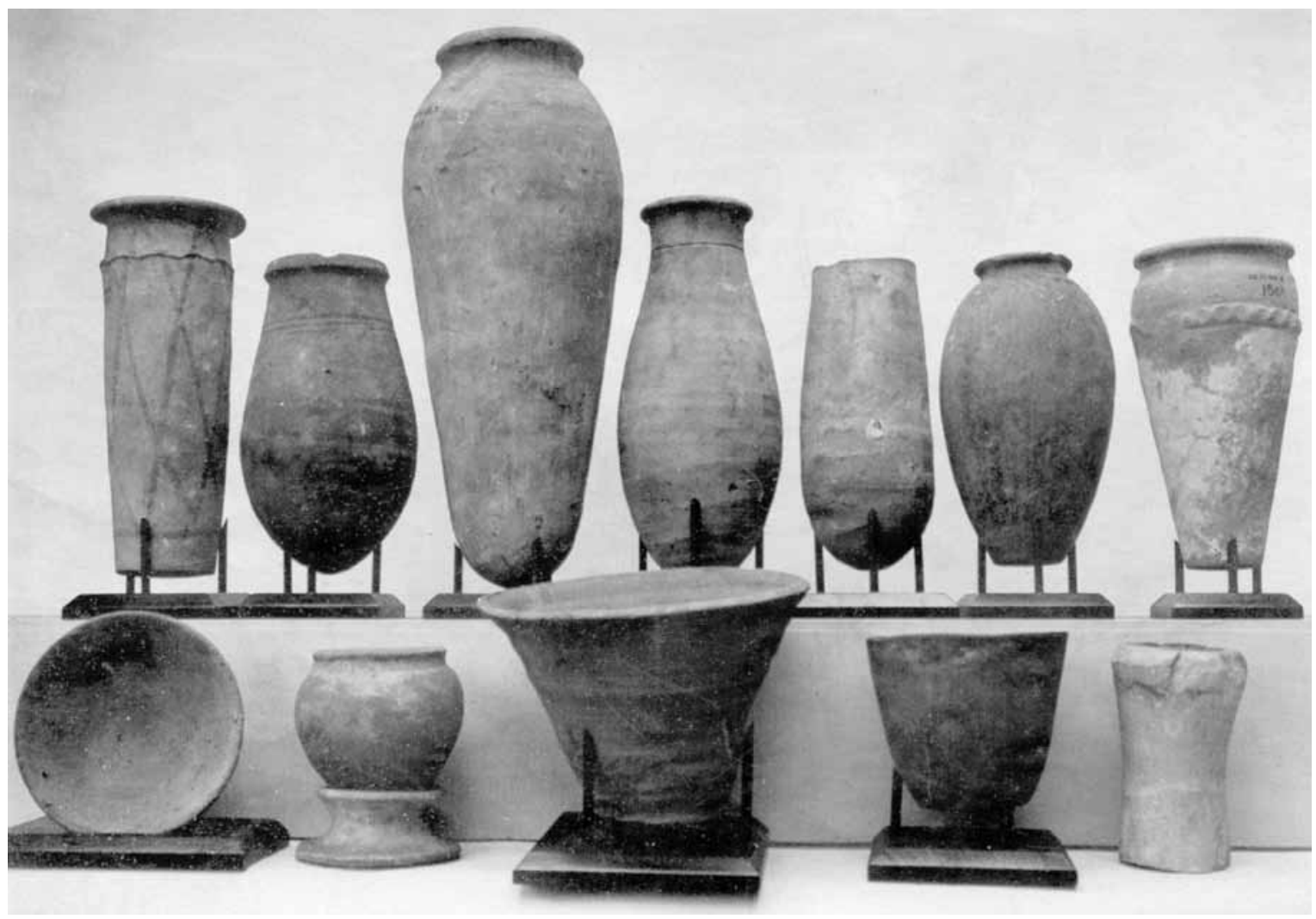

Figura 2. Foto enviada por Entwistle con motivo del intercambio 


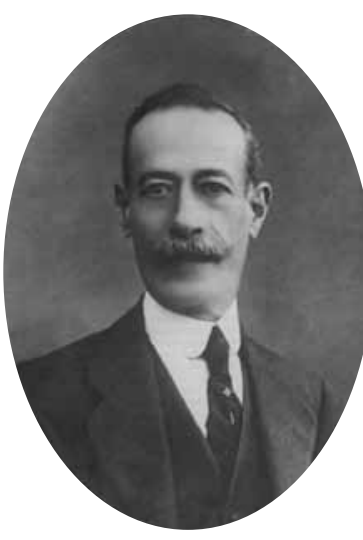

Figura 3.

Teodomiro Robayna

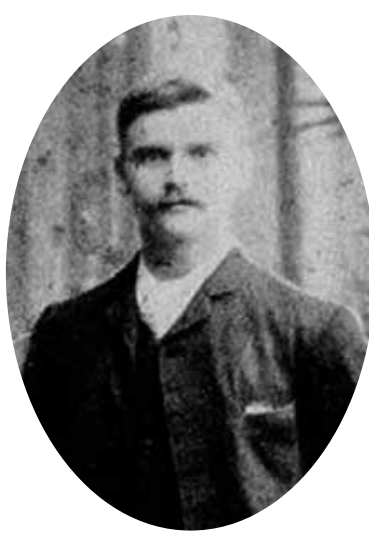

Figura 5.

Peter Entwistle

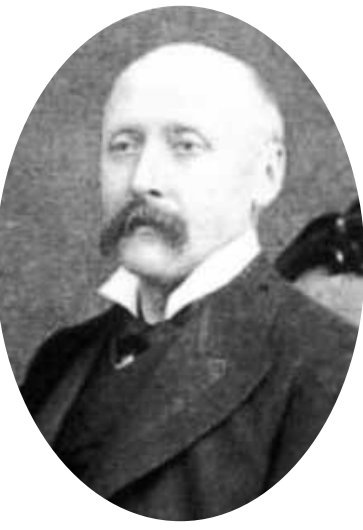

Figura 4. Henry O. Forbes

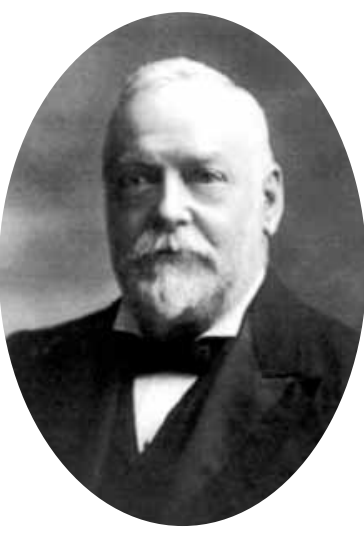

Figura 6. Arnold Ridyard la documentación disponible solicitó que se le mandaran unos ejemplares de pájaros "canarios" junto a los azulejos.

En cuanto a la persona a quien debemos la gestión del intercambio fue, como ya se ha indicado, Peter Entwistle, especialista en cerámica antigua y conservador del Museo de Liverpool, al que dedicó más de cincuenta años de vida profesional (fig. 5). Por aquella época, la política de la institución inglesa pasaba por ampliar sus colecciones, y ello favorecía que Entwistle aprovechara sus vacaciones para visitar los organismos culturales de las ciudades por las que pasaba y ofrecerles una permuta de objetos.
Cuando se produjo el acuerdo entre ambos directores, se anunció en una carta que Arnold Ridyard, jefe de máquinas de un barco de la compañía de vapores Elder, se ocuparía de transportar y entregar los materiales (fig. 6). Cuando iniciamos el estudio de la colección, especulamos con la posibilidad de que Entwistle le eligiera como intermediario al haberle conocido durante los días de travesía entre Canarias y Liverpool. Sin embargo, hoy se sabe con certeza que Ridyard era algo más que un trabajador de la compañía Elder. Gracias a la navegación entre Liverpool y Opobo (Golfo de Guinea) y aprovechando los atraques que su vapor hacía en diferentes puntos de África occidental, llegó a adquirir más de dos mil quinientas piezas etnográficas para el Museo de Liverpool. Actualmente esta considerado como el principal donante de este tipo de materiales a la citada institución (Hill, 2005: 61, 81; sitio web del Liverpool Museum).

El navío en el que se trasladaron los objetos del intercambio fue el S.S. Addah, un vapor de la afamada Compañía Elder and Demptser, cuyas sedes en Tenerife y Las Palmas de Gran Canaria gestionaban un gran trasvase de mercancías y pasajeros. Curiosamente, este barco tendría un final tan ligado a los avatares de la Historia como su inusual cargamento egipcio, pues fue hundido el 15 de junio de 1917 frente a la costa francesa, tras combatir con un submarino alemán en la Primera Guerra Mundial (fig. 7) (Elder, 1921; Wrecksite Database; Ajax, 1918: 99-101).

En este texto se han ofrecido breves referencias sobre las entidades implicadas en el canje y parece lógico ilustrarlo con algunas imágenes retrospectivas de ambas. Para el Museo tinerfeño presentamos la única foto que se ha podido localizar del edificio mostrando el rótulo "Museo Municipal" en su entrada (fig. 8). Fue demolido en los años 30 del siglo 


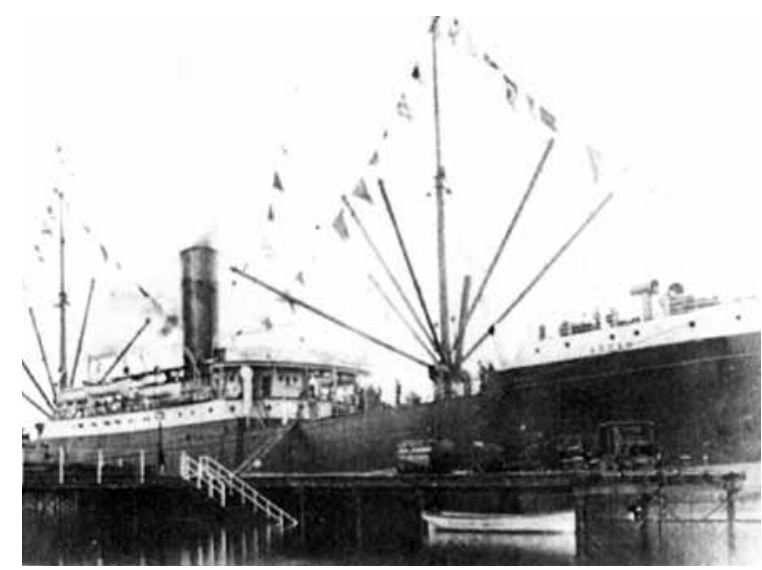

Figura 7. Buque a vapor S.S. Addah, de la Compañia Elder and Demptser

$\mathrm{XX}$, a excepción de la torre y de su cúpula, que aún se pueden reconocer engullidas por la nueva construcción. Respecto al Museo de Liverpool, se ha optado por presentar dos fotografías que muestran la sala egipcia antes y después de un ataque aéreo alemán en mayo de 1941 (fig. 9 y 10). Alcanzada por una bomba incendiaria, la institución ardió durante horas afectando tanto a las salas como a los departamentos de documentación. En lo que a su colección egipcia se refiere, representó la pérdida de gran parte de sus fondos, que se encontraban aún expuestos, ya que únicamente una parte había sido evacuada a diferentes refugios. Sólo se salvaron algunos objetos de piedra. En los años 60, iniciaron un proceso de búsqueda de las piezas que habían salido del museo debido a diferentes acuerdos. La directora de la sección de arqueología, Dorothy Downes, remitió el 12 de marzo de 1968 una carta al Museo de Bellas Artes de Tenerife en la que requería información sobre las piezas intercambiadas con el fin de realizar un cálculo real de qué parte de sus fondos habían sido destruidos durante la guerra. Sin embargo, nunca recibió contestación al estar vacante por entonces el puesto de director.

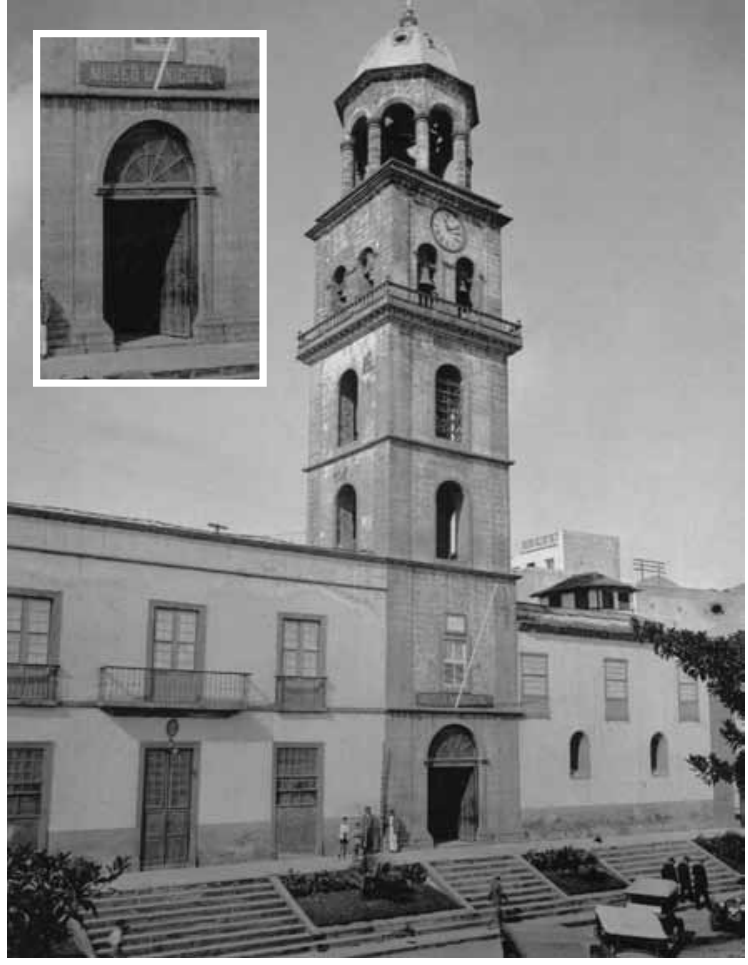

Figura 8. Sede del Museo Municipal de Bellas Artes de Santa Cruz de Tenerife a comienzos de 1908 y rótulo identificativo
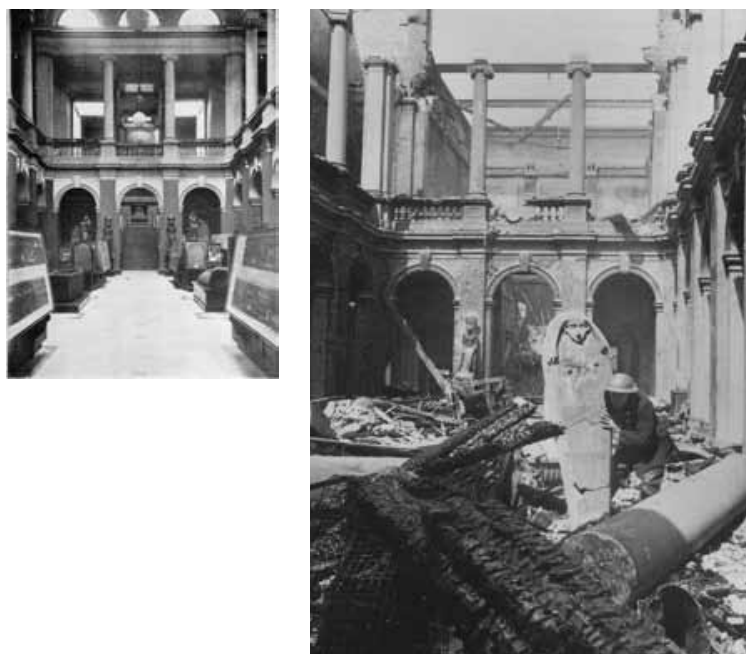

Figuras 9 y 10. Sala egipcia del Museo de Liverpool antes y después de un ataque aéreo alemán en mayo de 1941 
Así, las piezas fueron consideradas como desaparecidas o no localizadas, tal como lo atestiguan diversas obras (Downes, 1974: 116-132; Bienkowsky y Southworth, 1986; Adams, 1987: 216 y 218). Por nuestra parte, las consultas que hemos realizado al museo inglés acerca de los azulejos recibidos, han dado un resultado negativo, pues no se han localizado en la institución, por lo que esto nos hace pensar que corrieron la misma suerte que la colección egipcia. No obstante, mantenemos la esperanza de que aparezcan entre los materiales que aún se siguen recuperando en los lugares en que se depositaron durante la guerra.

La labor investigadora puede generar nuevos indicios inesperados. La nuestra ha sido un ejemplo de ello, ya que en el verano de 2006 nos vimos sorprendidos por la noticia de la existencia de otro intercambio del Museo de Liverpool en el Archipiélago. En un legajo conservado en el archivo de esta institución se registraba el curriculum vitae que Entwistle entregó al Museo con vista a su ascenso en 1926. En él aparecía una relación de ciudades y lugares con cuyas instituciones había entablado contactos, y entre ellas se menciona un Museo Canario de Gran Canaria y el Museo de Tenerife, como puede leerse en la siguiente cita:

At Grand Canary I found the only rock where Anemones had been found previously by the late Isaac Thompson. From the Canary Museum I brought back Guanche remains, and from Teneriffe roofing tiles etc., from the dome of the Museum -an old Monastery- and also arranged an exchange. (Nightingale, 2007)

De la lectura de este párrafo se dedujo la posible existencia de un trueque de diversos materiales de la cultura de la isla por un conjunto de piezas egipcias. Contactamos con el Museo Canario de Las Palmas de Gran Canaria con el objetivo de verificar si existían pruebas de esa relación. Los conservadores nos confirmaron que se había producido un flujo de misivas entre ambos museos, como había sucedido con el tinerfeño. El posible intercambio fue estudiado durante dos reuniones de la Junta Directiva del Museo Canario. En ellas se informó a los asistentes de que los británicos ofrecían cerámicas, utensilios de piedra y pedernal y que solicitaban que se les enviara a cambio cráneos guanches, vasijas, pintaderas, molinos y cualquier otro objeto aborigen que se creyese oportuno ${ }^{3}$. Al contrario que con el Museo de Bellas Artes, se produjo un debate, ya que si bien Luis Millares, el Presidente, estaba totalmente a favor, el Secretario se oponía por diferentes razones. Ante este dilema, la Junta concedió la decisión última al primero. Los datos desprendidos de tales documentos, nos hicieron concebir esperanzas de que se hubiese llevado a cabo dicho trato. No obstante, y pese a la ardua labor de búsqueda que sigue realizando su conservadora, Carmen Cruz, aún no se ha localizado rastro material de la transacción. En la documentación del archivo, tampoco han podido ser localizadas las cartas originales, las fotografías o los listados de piezas que deberían acompañarla, lo que ha limitado enormemente el seguimiento. Su hallazgo permitiría confirmar la existencia de la permuta e identificar el tipo de materiales enviados, dando así un paso en la verificación de su salida de Liverpool y el proceso hasta su llegada a esta ciudad. Ante la ausencia de información, hemos concebido la posibilidad de que el intercambio pudiera darse a título personal con algún miembro del Museo Canario y no con la propia entidad, lo que haría aún más difícil su localización.

Dada la singularidad del proceso de reparto y distribución de piezas egipcias que existió antes de 1923 (Molinero Polo, 1988: 52-56), se hace necesario dedicar atención a los museos loca-

3. Libro de Actas de las Juntas Directivas de El Museo Canario (sesiones de 13 de enero y 6 de abril, 1908). 
les, muchas veces desconocidos en el circuito egiptológico, pues pueden darnos sorpresas, tal y como ocurrió con la colección egipcia de Tenerife. La política de intercambios entre instituciones y particulares propia de finales del XIX y principios del XX, ha complicado aún más la situación actual, propiciando que materiales de campañas arqueológicas importantes hayan quedado dispersos y olvidados. Baste consultar ciertas páginas de Internet para sorprenderse con el gran número de pequeñas entidades con colecciones egipcias. Un ejemplo para Gran Bretaña es http://www.cornucopia.org.uk/, donde se encuentra registrado un alto número de museos e instituciones, tanto locales como nacionales de las Islas Británicas, con la referencia a sus fondos. Esto facilita la localización de inusuales depósitos, muchas veces almacenados durante décadas en cajas y sin registro, en castillos y casas señoriales. La recuperación de estos, es un elemento indispensable para recopilar los objetos de las excavaciones antiguas, lo que nos permitiría evaluar y reinterpretar diversos aspectos que quedan inciertos en los informes y memorias. 


\section{Bibliografía}

Adams, B.

1987 The Fort Cemetery of Hierakonpolis. Kent.

AJAX, X.

1918 The German Pirate: His Methods and Record. New York.

Almenara, E.; Martín del Río, C.

2000a Colección de Vasos Egipcios del Museo de Bellas Artes de Santa Cruz de Tenerife. Santa Cruz de Tenerife.

2000b El largo viaje del patrimonio egipcio. El ejemplo de la colección del Museo de Bellas Artes de Santa Cruz de Tenerife, en Molinero Polo, M.Á.; Sola Antequera, D. (coords.): Arte y sociedad del Egipto antiguo, Madrid: 254-265.

BiEnKowsky, P.; Southworth, E.

1986 Egyptian Antiquities in the Liverpool Museum. I. A List of the Provenanced Objects. Paris.

DOWNES, D.

1974 The Excavation at Esna, 1905-1906. Warminster.

Elder Dempster Co., LtD.

1921 The Elder Dempster Fleet in the War, 1914-1918. Liverpool.
HiLl, K.

2005 Culture and class in English public museums, 1850-1914. Ashgate.

Liverpool Museum:

http://www.liverpoolmuseums.org.uk/ wml/humanworld/worldcultures/africa/ chiefcollector.aspx.

Consultado en enero de 2008.

Molinero Polo, M.Á.

1988 De la creación del IFAO a la Primera Guerra Mundial, en Molinero Polo, M.Á.; Pérez-Accino, J.R.; Pérez Largacha, A.; Sevilla Cueva, C. (coords.): Egipto. Doscientos años de investigación arqueológica, Madrid: 44-65.

Nightingale, B.

http://www.entwistlefamily.org.uk/memoirs.htm.

Consultado en invierno de 2007.

Wrecksite Database:

http://www.wrecksite.eu/wreck. aspx?85762.

Consultado en enero de 2008. 


\section{Trabajos de Egiptología Papers on Ancient Egypt}

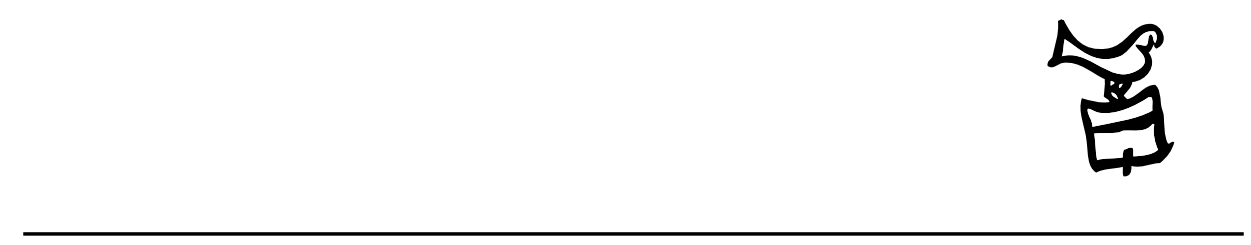

Número 5/1 2009 


\section{Actas \\ III Congreso Ibérico de Egiptología III Congresso Ibérico de Egiptologia}

Editores

Miguel Ángel Molinero Polo Covadonga Sevilla Cueva 


\title{
Editor
}

Miguel Ángel Molinero Polo

Universidad de La Laguna

\section{Consejo Editorial}

\author{
Antonio Pérez Largacha \\ Universidad de Castilla-La Mancha \\ José-R. Pérez-Accino \\ Birkbeck, Universidad de Londres \\ Covadonga Sevilla Cueva \\ Universidad Autónoma de Madrid
}

\section{Comité Científico}

Josep Cervelló i Autuori

Universitat Autònoma de Barcelona

$\mathrm{M}^{\mathrm{a}}$ José lópez Grande

Universidad Autónoma de Madrid

Josep Padró i Parcerisa

Universitat de Barcelona

$\mathrm{M}^{\mathrm{a}}$ Carmen Pérez Die

Museo Arqueológico Nacional, Madrid

Ester Pons Mellado

Museo Arqueológico Nacional, Madrid

José M. Serrano Delgado

Universidad de Sevilla

\section{Colaboradores Editoriales}

Linda Steynor

English editorial assistant

Hervé Mouriacoux

Assistant éditorial pour la langue française 
Trabajos de Egiptología está producida por Isfet. Egiptología e Historia c/ Blanco $1,2^{\circ}$

38400 Puerto de la Cruz

Tenerife-Islas Canarias

España

Maquetación: Proyecto Limón

(C) Autores de los artículos aparecidos

y Consejo Editorial de Trabajos de Egiptología - Papers on ancient Egypt

Depósito Legal: TF-2302-2009

ISSN: $1695-4750$

Imprime: Gráfica Los Majuelos, S.L.L.

imprenta@graficaslosmajuelos.com

Tfno.: 922311455 


\section{Comité Científico \\ III Congreso Ibérico de Egiptología III Congresso Ibérico de Egiptologia}

Miguel Á. Molinero Polo

Universidad de La Laguna

Presidente del Comité Organizador del III Congreso Ibérico de Egiptología

Miembro del Comité Organizador del I Encuentro de Egiptología

Josep Cervelló Autuori

Universitat Autònoma de Barcelona

Presidente del Comité Organizador del II Congreso Ibérico de Egiptologia

José Manuel Galán Allué

Consejo Superior de Investigaciones Cientificas

Director del Proyecto Djehuty, Luxor, Egipto

$\mathrm{M}^{\mathrm{a}}$ Helena Trindade Lopes

Universidad de Lisboa

Directora de la Misión Arqueológica Portuguesa en Menfis

Josep Padró i Parcerisa

Universitat de Barcelona

Director de la Misión Arqueológica de Oxirrinco

Antonio Pérez Largacha

Universidad de Castilla - La Mancha

Miembro del Comité Organizador del I Encuentro de Egiptología

José Ramón Pérez-Accino

Birkbeck College, University of London

Miembro del Comité Organizador del I Encuentro de Egiptología

$\mathrm{M}^{\mathrm{a}}$. Carmen Pérez Díe

Museo Arqueológico Nacional

Directora de la Misión Arqueológica Española en Heracleópolis Magna, Egipto

Covadonga Sevilla Cueva

Universidad Autónoma de Madrid

Miembro del Comité Organizador del I Encuentro de Egiptología 